\title{
THE ANCIENT JERUSALEM PUBLICATIONS SERIES
}

The City of David, the Gihon Spring, the Ophel, Mount Zion, the Valley of Ben Hinnom, the Kidron Valley are all located south and east of the Old City of Jerusalem. They are all cast in the shadows of the Temple Mount, all are engulfed in millennia of history and religion, and all are nestled in the city's most beautiful, breathtaking and dramatic landscape.

It is here in this area that the city of Jerusalem was born. Here, towards the bottom of the Old City and near the Gihon Spring, the city's only source of water and hence its raison d'être, that the ancient city grew, where a Canaanite culture that worshipped the god Shalem flourished and gave the city its name, Urušalim, which it bears to this day. It is here that David established his capital, and Solomon, his son and successor, built his Temple, in the light of which the Hebrew Bible was composed and the city burgeoned and in the shadow of which it fell into ruins. And it is here too where each successive period etched its own unique character and contribution.

New cities grew from the ashes of the old, with each stratum adding its own characteristics. But the urban and architectural connection between the area south of the Temple Mount and the sacred compound on the eastern hill endured.

For the past 160 years, archaeological excavations have been carried out all over this city on a massive scale, both in terms of personnel and duration of work. The impressive scale of this research activity has led to numerous discoveries that have enabled archaeologists and historians to take a clear, critical look at the culture of the ancient city, its physical and urban features, and its settlement strata.

Most of these excavations were carried out on behalf of the Israel Antiquities Authority (IAA); two were conducted as part of a joint archaeological research project of the IAA and Tel Aviv University, with scholars from leading research institutes and disciplines in Israel and abroad taking part.

While articles on these excavations have been published, they have been published in an unsystematic manner. While a few comprehensive reports on IAA excavations have appeared in distinguished academic journals, a large gap has developed: the fieldwork and preliminary academic research are extensive, but the level and quality of the final publications of those excavations are very limited. Until now there has been no organized, peer-reviewed forum for the publication of research on these excavations. The Center for the Study of Ancient Jerusalem and its publications division, The Ancient Jerusalem Publication Series, were created in order to rectify this situation.

The Center for the Study of Ancient Jerusalem is the IAA's auxiliary research branch for the advancement of excavations and research currently being conducted in ancient Jerusalem. It was established by the Jerusalem Region of the IAA, in consultation with Amutat EL-AD, which runs the City of David and other ancient Jerusalem sites.

The Center was founded in 2018 as a focal point for the study of and in-depth research on the archaeology and history of ancient Jerusalem. Its aim is to create research infrastructure for archaeological excavations, to cultivate knowledge, and to present this knowledge to the academic community and the general public. The Center promotes the academic publication of excavations pertaining to ancient Jerusalem, as well as peer-reviewed publications of other works on various topics and of catalogs; grant stipends and awards to scholars for the purpose of furthering 
archaeological research related to ancient Jerusalem; it also organizes workshops, seminars and local and international conferences.

It was only natural for the academic committee of the publication series to choose to begin publication with the results of excavations and research studies conducted by Ronny Reich and Eli Shukron at several areas in the City of David. These excavations augured a new era of largescale archaeological research that began in 1995 as a modest tourism development project at archaeological sites in connection with Jerusalem's 3000th anniversary celebrations the following year. The project is still underway.

The publication of this volume by the IAA and the Center for the Study of Ancient Jerusalem would not have been possible without the dedication and talents of the editorial staff of the series under the leadership of Efrat Bocher, the series editor; Dr. Joe Uziel, editor; and Myrna Pollak, managing editor; as well as Dr. Anat Mendel-Geberovich, associate editor; Alina Yoffe-Pikovsky, graphics editor; Hanania Rothner, proofreader. The manuscript was critically reviewed, beginning to end, by Dr. Yiftah Shalev and Dr. Danny Syon; Debora Sandhaus and Dr. Liora Freud reviewed the chapters on the finds.

It is my pleasure and duty to thank all those who helped me to successfully achieve the establishment of the Center for the Study of Ancient Jerusalem: Michael Baruchi, who took it upon himself to handle the administrative and logistic side of operations; Yoav Tzionit who helped draw up work plans and offered wise advice; Tiffany Touitou, Oshrit Faragi Hazon and Isabel Rosenbaum Bracha, who helped with office management; Osnat Assouline, who managed the Center's budget; Yehonatan Ben-Kasus, who worked selflessly organizing the excavation finds; Amit Re'em, attorney Aharon Heiman, Oriya Dasberg and Doron Spielman; and above all Amutat El'ad director David Be'eri; and to Israel Hasson, the director of the Israel Antiquities Authority, who recognized the importance of this cultural and intellectual project. All of them put so much of their energies into ensuring the success of this project. I cannot thank them enough.

My final gratitude is reserved for a very special person and family. While the archeological research being performed in Jerusalem rests largely on the shoulders of the archeologists and the scientists who work in the field and in the laboratory to bring these findings to life, none of these efforts would be possible if it were not for the generous assistance of a select group of visionaries who have had the wisdom, insight and intellectual curiosity to support this important work.

The Shvidler family, and at their head Eugene Shvidler, are not just one of these pioneering families, they are the very symbol of the great level of impact that a single person and a single family can make, by underwriting an archaeological renaissance at one of the world's most important archaeological sites, the City of David.

Yuval Baruch 
M.t.

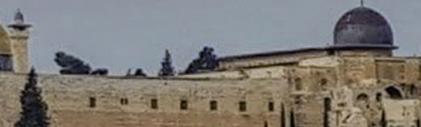

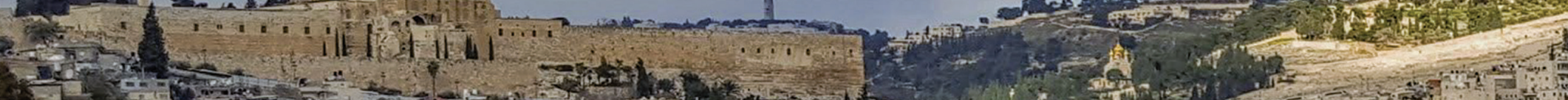

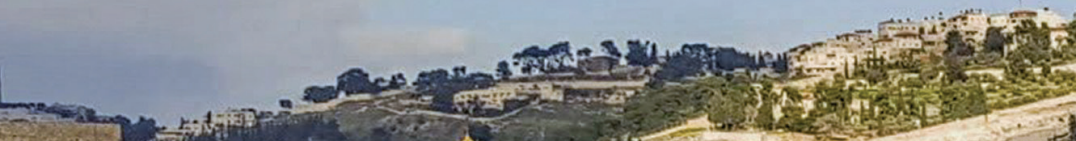

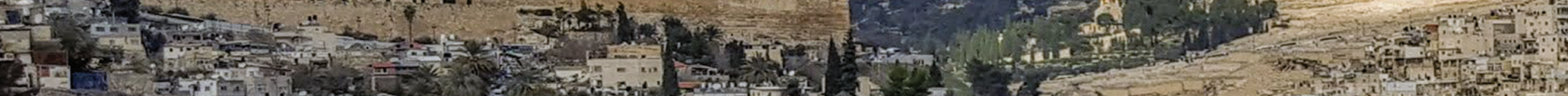

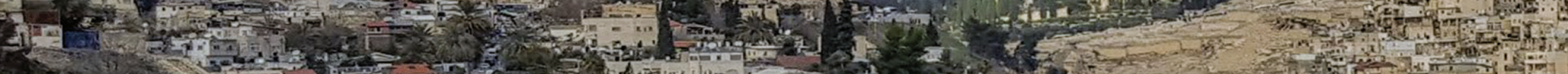

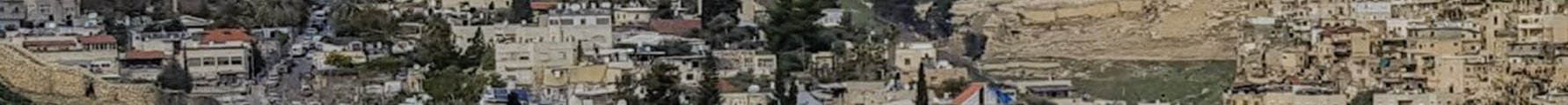

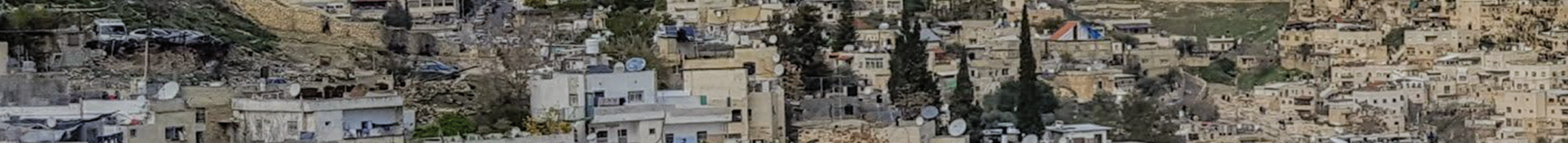
7. W : II

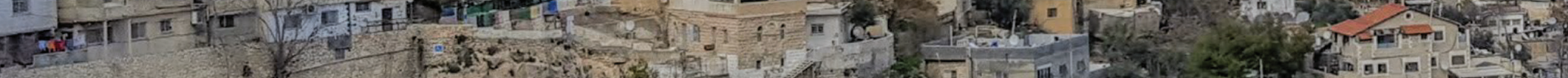
4 (5)

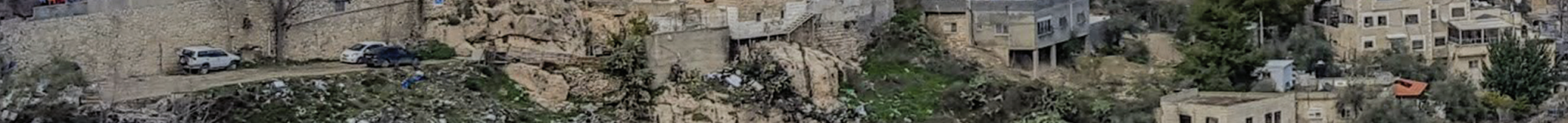

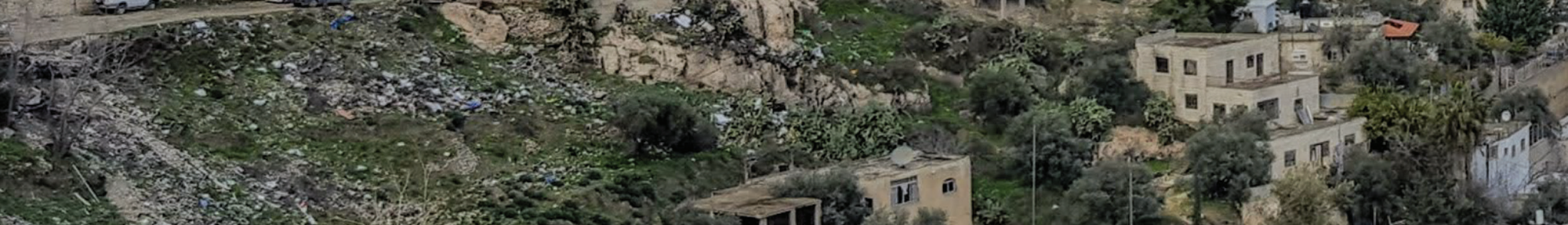

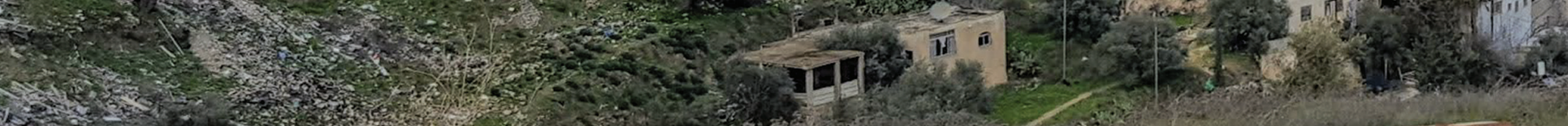

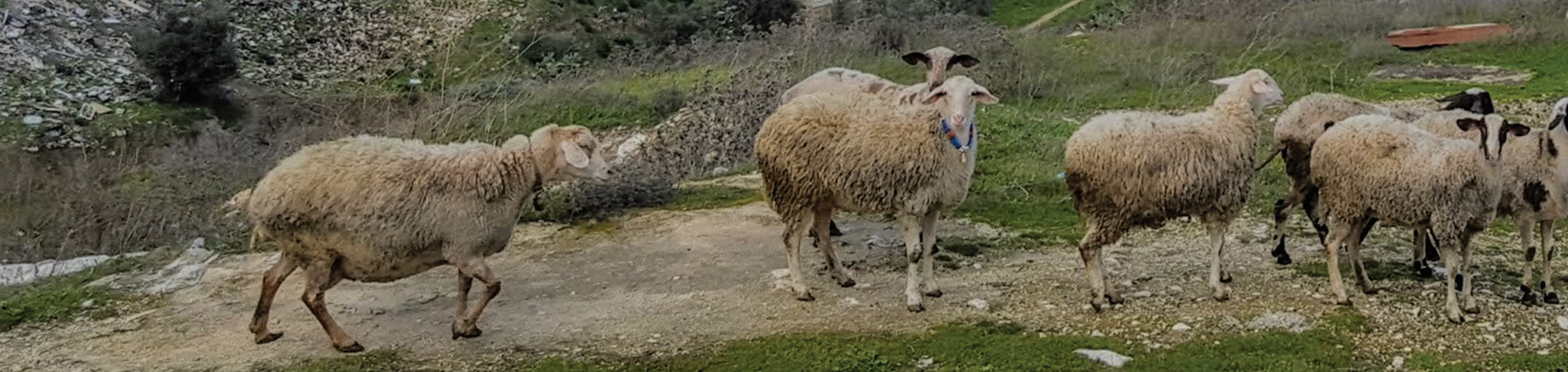

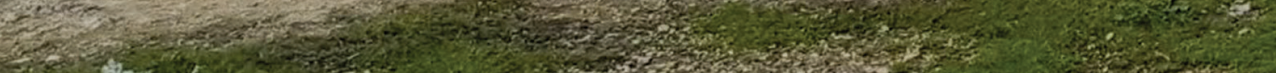
a. $x$

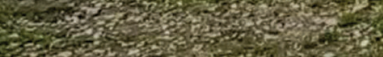


12.4.

(1)

-

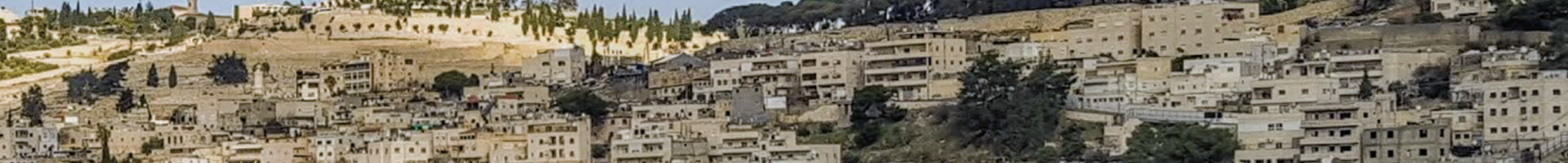

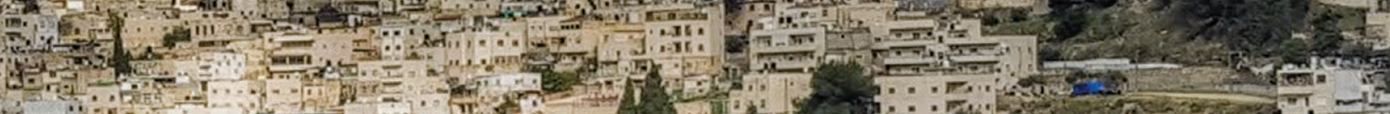

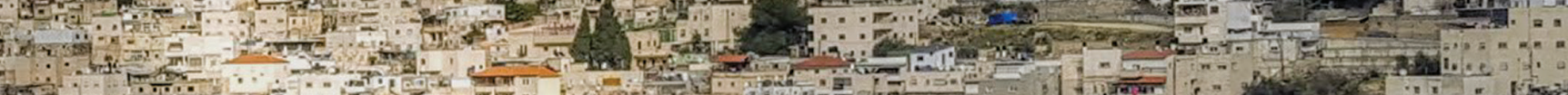

2.

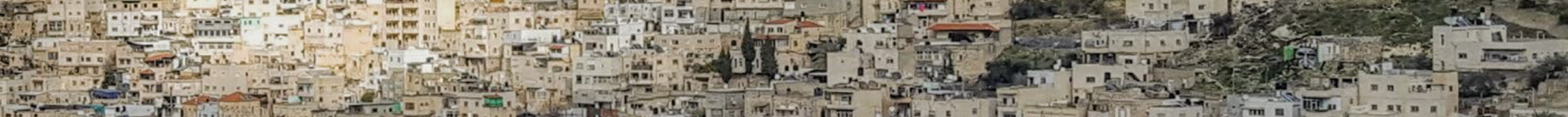

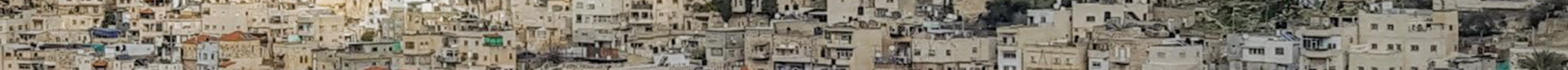

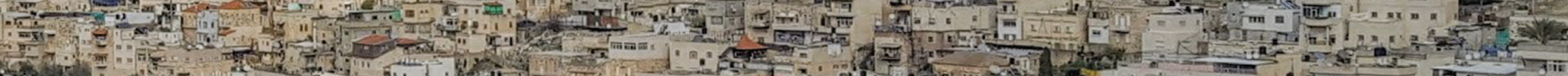

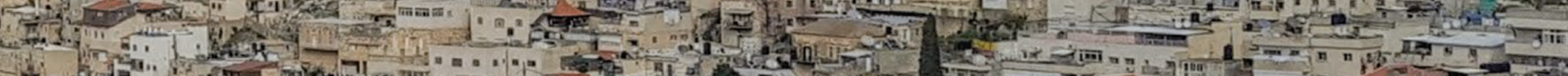
1.

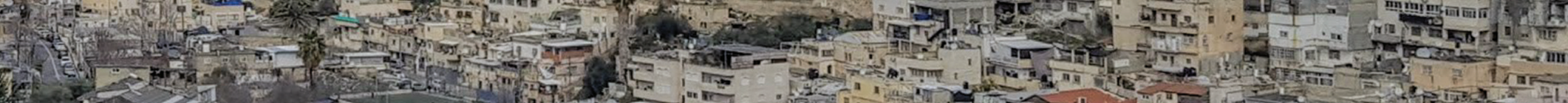

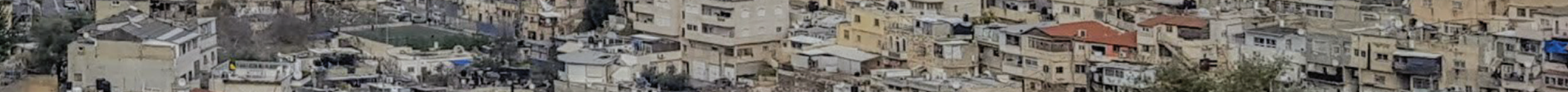

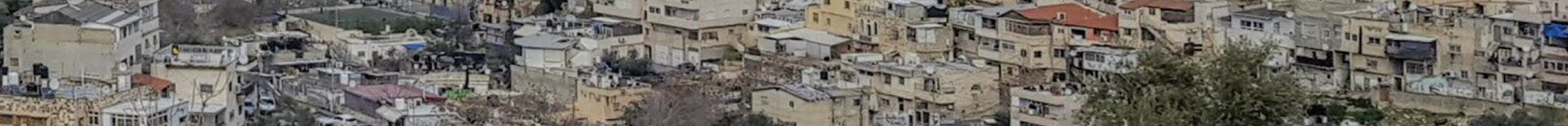
T.

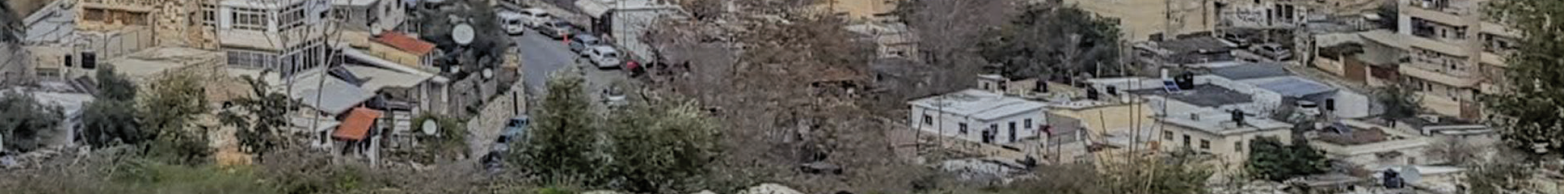

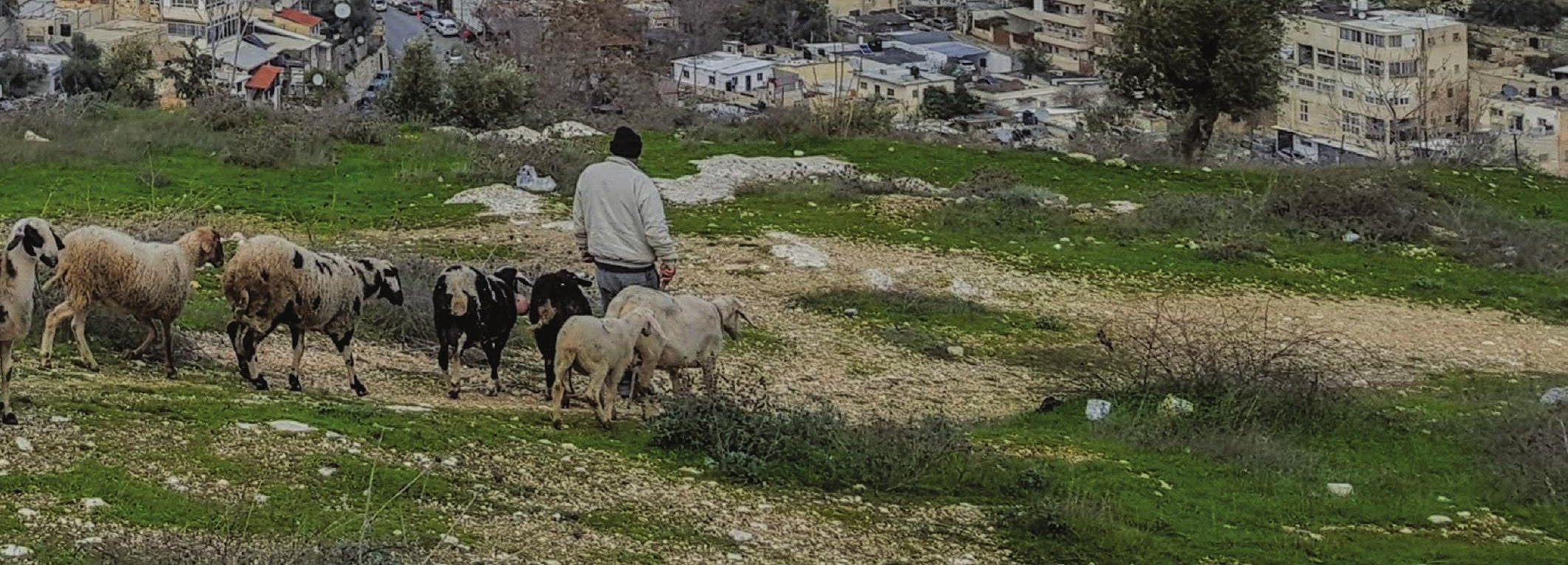


